\title{
Characteristics Research of a High Sensitivity Piezoelectric MOSFET Acceleration Sensor
}

\author{
Chunpeng Ai, Xiaofeng Zhao and Dianzhong Wen * \\ Key Laboratory of Electronics Engineering College of Heilongjiang Province, Heilongjiang University, \\ Harbin 150006, China; aichunpeng@hlju.edu.cn (C.A.); zhaoxiaofeng@hlju.edu.cn (X.Z.) \\ * Correspondence: wendianzhong@hlju.edu.cn; Tel.: +86-0451-8660-8413
}

Received: 29 July 2020; Accepted: 1 September 2020; Published: 3 September 2020

\begin{abstract}
In order to improve the output sensitivity of the piezoelectric acceleration sensor, this paper proposed a high sensitivity acceleration sensor based on a piezoelectric metal oxide semiconductor field effect transistor (MOSFET). It is constituted by a piezoelectric beam and an N-channel depletion MOSFET. A silicon cantilever beam with $\mathrm{Pt} / \mathrm{ZnO} / \mathrm{Pt} / \mathrm{Ti}$ multilayer structure is used as a piezoelectric beam. Based on the piezoelectric effect, the piezoelectric beam generates charges when it is subjected to acceleration. Due to the large input impedance of the MOSFET, the charge generated by the piezoelectric beam can be used as a gate control signal to achieve the purpose of converting the output charge of the piezoelectric beam into current. The test results show that when the external excitation acceleration increases from $0.2 \mathrm{~g}$ to $1.5 \mathrm{~g}$ with an increment of $0.1 \mathrm{~g}$, the peak-to-peak value of the output voltage of the proposed sensors increases from $0.327 \mathrm{~V}$ to $2.774 \mathrm{~V}$ at a frequency of $1075 \mathrm{~Hz}$. The voltage sensitivity of the piezoelectric beam is $0.85 \mathrm{~V} / \mathrm{g}$ and that of the proposed acceleration sensor was $2.05 \mathrm{~V} / \mathrm{g}$, which is 2.41 times higher than the piezoelectric beam. The proposed sensor can effectively improve the voltage output sensitivity and can be used in the field of structural health monitoring.
\end{abstract}

Keywords: piezoelectric MOSFET; piezoelectric beam; acceleration sensor; high sensitivity

\section{Introduction}

Micro-electro-mechanical system (MEMS) acceleration sensors, with the advantages of low cost, low power consumption, high compatibility with integrated circuit (IC) process and high integration [1-4], have a wide range of applications in automotive electronics, structural health monitoring, navigation and other fields [5-8]. MEMS acceleration sensors usually include piezoresistive [9,10], capacitive [11] and piezoelectric acceleration sensors [12,13]. Piezoresistive accelerometer usually consists of a deformable structure and varistors. Under the action of external acceleration, the deformation of the deformable structure causes the resistance of the varistor to change, thereby measuring the acceleration. The varistors are usually made into a Wheatstone bridge structure to improve the output sensitivity. The piezoresistive accelerometer has the advantages of good stability, wide measurement range, and is also limited by ambient temperature [14-16]. A capacitive acceleration sensor is composed of fixed plates and movable plates. The gap or area of the plate capacitor changes while the external acceleration is applied. The applied acceleration is obtained by measuring the change of capacitance. High sensitivity and zero frequency response are its advantages, while its disadvantages are high impedance and nonlinearity [17-19]. The working principle of the piezoelectric acceleration sensor is similar to that of the piezoresistive type, but the difference is that the piezoresistive material is replaced by piezoelectric material. Compared with piezoresistive and capacitive MEMS acceleration sensors, piezoelectric MEMS acceleration sensors have advantages of low power cost and high range 
of applying frequency; at the same time, they are also limited by high output impedance, weak output signal and so on [20-23].

The researchers are committed to improving the structure of the piezoelectric acceleration sensor so as to improve its performance, especially its sensitivity. For example, Jin Xie et al. present a MEMS piezoelectric in-plane resonant accelerometer with a two-stage microleverage mechanism. The sensitivity of the device is $28.4 \mathrm{~Hz} / \mathrm{g}$ and the relative sensitivity is $201 \mathrm{ppm} / \mathrm{g}$ at the base frequency around $140.7 \mathrm{kHz}$, which are $57 \%$ and $268 \%$ higher than previously reported data [24]. Qiang Zou et al. reported novel single- and tri-axis piezoelectric-bimorph accelerometers that are built on parylene beams with $\mathrm{ZnO}$ thin films. A highly symmetric quad-beam bimorph structure with a single proof mass is used for tri-axis acceleration sensing. The unamplified sensitivities of the $x$-axis, $y$-axis, and $z$-axis are $0.93,1.13$, and $0.88 \mathrm{mV} / \mathrm{g}$, respectively [13]. At the same time, the researchers also studied the doped piezoelectric materials in order to improve the piezoelectric properties so as to improve the sensitivity. Ramany et al. presented a nano-electro-mechanical systems accelerometer using undoped zinc oxide nanorods and $1 \mathrm{wt}$. (Weight) $\%, 3 \mathrm{wt} . \%$ and $5 \mathrm{wt} . \%$ of vanadium-doped zinc oxide nanorods as an active layer. The highest sensitivity of $3.528 \mathrm{~V} / \mathrm{g}$ was acquired for $5 \mathrm{wt} . \%$ of vanadium-doped zinc oxide with maximum output voltages of $2.30 \mathrm{~V}$ and $2.9 \mathrm{~V}$ at $9 \mathrm{~Hz}$ resonant frequency and $1 \mathrm{~g}$ acceleration, respectively [25].

In this work, by taking advantage of the high gate sensitivity of MOSFET, in order to improve the output sensitivity and reduce the output impedance of piezoelectric acceleration sensors, we designed a piezoelectric MOSFET acceleration sensor (PMAS) structure. The PMAS with high sensitivity can be used in acceleration monitoring under special frequency vibration environments, such as health monitoring on turning tools.

\section{Basic Structure and Operating Principle}

\subsection{Basic Structure}

The structure of PMAS is shown in Figure 1a. It consists of a piezoelectric beam and an N-channel depletion MOSFET. The piezoelectric beam is a two-ended device: one end is connected with the source of MOSFET as the ground terminal of PMAS, the other end is connected with the gate of MOSFET to control the output current of MOSFET, and the drain of MOSFET is the current output terminal of PMAS. The direction of the measured acceleration is parallel to the $z$-axis as shown in Figure 1a. The acceleration applied by the vibration system is reciprocating up and down along the $z$-axis. Therefore, the output signal of the piezoelectric beam is a sinusoidal signal with a certain frequency. The N-channel depletion MOSFET is chosen to ensure that the MOSFET works in the triode region. As shown in Figure 1b, a load resistance $R_{\mathrm{L}}$ is used in series with PMAS to convert the current signal into a voltage signal for output.

(a)

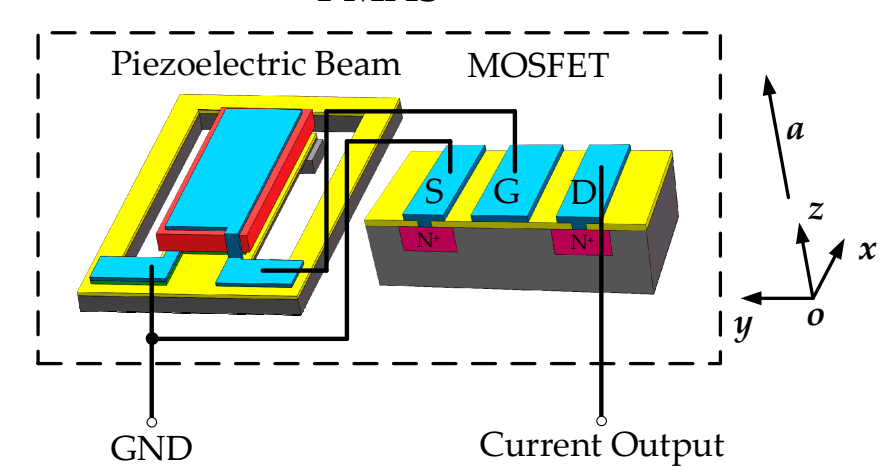

(b)

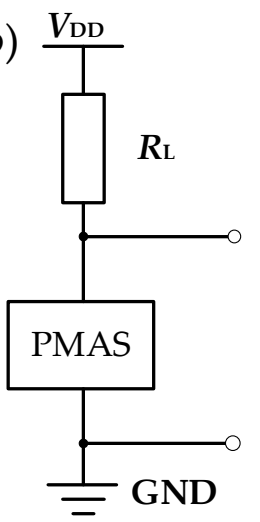

Figure 1. Basic structure and test circuit of piezoelectric metal oxide semiconductor field effect transistor (MOSFET) acceleration sensor (PMAS): (a) basic structure; (b) test circuit. 
The structure of the piezoelectric beam is shown in Figure 2a, which consists of a silicon cantilever beam substrate with a proof mass and a piezoelectric multilayer structure. Silicon cantilever beam substrate is fabricated by lithography and inductive coupled plasma (ICP) etching technology. The piezoelectric multilayer structure, including electrodes (Pt top electrodes and $\mathrm{Pt} / \mathrm{Ti}$ composite bottom electrode) and a $\mathrm{ZnO}$ piezoelectric layer, was deposited by direct-current (DC) and radio frequency (RF) magnetron sputtering under the optimized parameters [26], respectively. Then, $5 \mathrm{wt} \% \mathrm{Li}$-doped $\mathrm{ZnO}$ was used as the piezoelectric layer. In general, $\mathrm{ZnO}$ is an n-type semiconductor due to the defects of oxygen vacancy and zinc interstitial atoms in the process of fabrication. After doping lithium as an acceptor impurity, the resistivity of $\mathrm{ZnO}$ is increased, thereby enhancing its piezoelectric properties. The piezoelectric beam is designed to be $9800 \times 5800 \times 500 \mu \mathrm{m}^{3}$ in size. Figure $2 \mathrm{c}$ shows the dimension of the cantilever beam. $l_{\mathrm{b}}, w_{\mathrm{b}}$ and $h_{\mathrm{b}}$ are the length, width and height of the cantilever beam, respectively. $l_{\mathrm{m}}, w_{\mathrm{m}}$ and $h_{\mathrm{m}}$ are the length, width and height of the proof mass, respectively. $l_{\mathrm{b}} \times w_{\mathrm{b}} \times h_{\mathrm{b}}$ was designed to be $6000 \times 2400 \times 80 \mu \mathrm{m}^{3}, l_{\mathrm{m}} \times w_{\mathrm{m}} \times h_{\mathrm{m}}$ was designed to be $1000 \times 2700 \times 395 \mu \mathrm{m}^{3}$. After the piezoelectric beam was manufactured, it was rigidly pasted on the customized test printed circuit board (PCB), and the piezoelectric beam's electrodes were connected with the PCB plate electrodes by a chip press welder (KNS4526, Kullicke \& Soffa, Haifa, Israel).
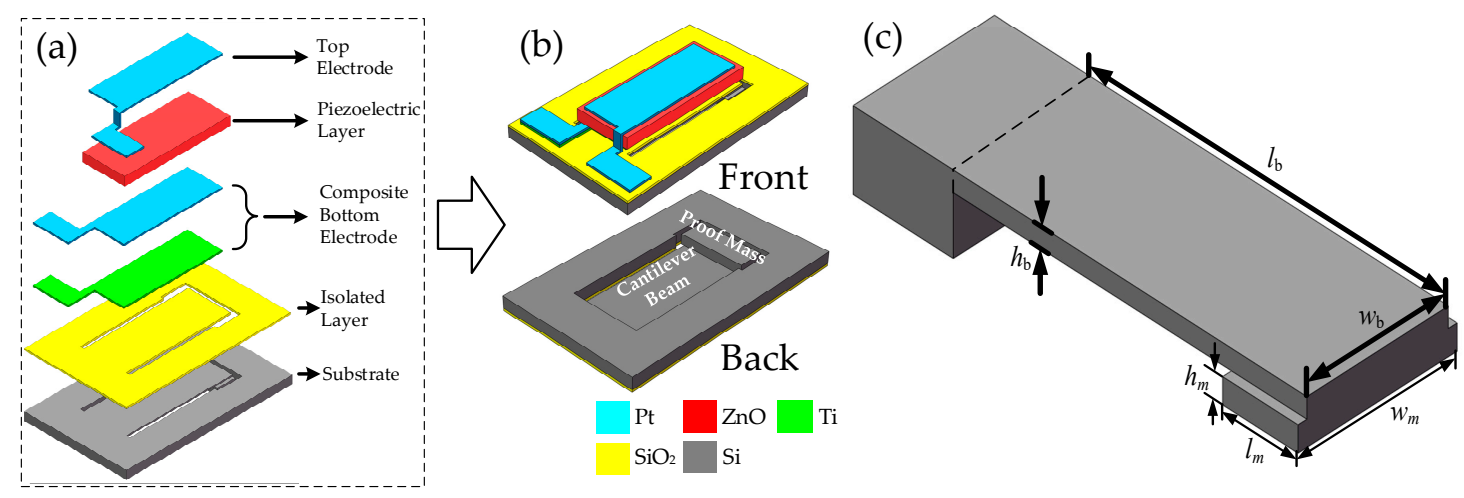

Figure 2. Basic structure of piezoelectric beam: (a) explosion view; (b) front and back side, (c) dimension of the cantilever beam.

\subsection{Operating Principle}

As shown in Figure 3a, the piezoelectric beam does not deform without external force. The centers of positive and negative charges in the piezoelectric layer coincide with each other; the whole piezoelectric layer is electrically neutral and there are no charge outputs. The PMAS also has a certain output when it is not affected by acceleration due to the existence of a conductive channel in the $\mathrm{N}$-channel depletion MOSFET even when the gate voltage is 0 . When external acceleration is applied, according to Newton's first and second laws, the proof mass will produce forces opposite to the acceleration direction due to the inertia, which can cause the piezoelectric beam to be deformed. At this time, the bending creates the electric dipole moment in the piezoelectric layer, forcing the positive and negative charge centers to separate. The same amount of charges of different signs are generated on the upper and lower surfaces of the piezoelectric layer. The generated charge is used as the gate signal of the MOSFET, which can directly control the width of the channel, thereby controlling the drain current of the MOSFET.

The stress analysis of the piezoelectric beam is shown in Figure $4 . d_{\mathrm{ZnO}}$ is the distance from the $\mathrm{ZnO}$ thin film to the bottom of the Si substrate, $d_{\mathrm{n}}$ is the distance from the neutral plane of the multilayer structure to the bottom of the $\mathrm{Si}$ substrate, $h_{1}, h_{2}, \ldots, h_{6}$ represent the thickness of $\mathrm{Si}, \mathrm{SiO} \mathrm{O}_{2}$, $\mathrm{Ti}, \mathrm{Pt}, \mathrm{ZnO}$ and Pt layers, respectively. 

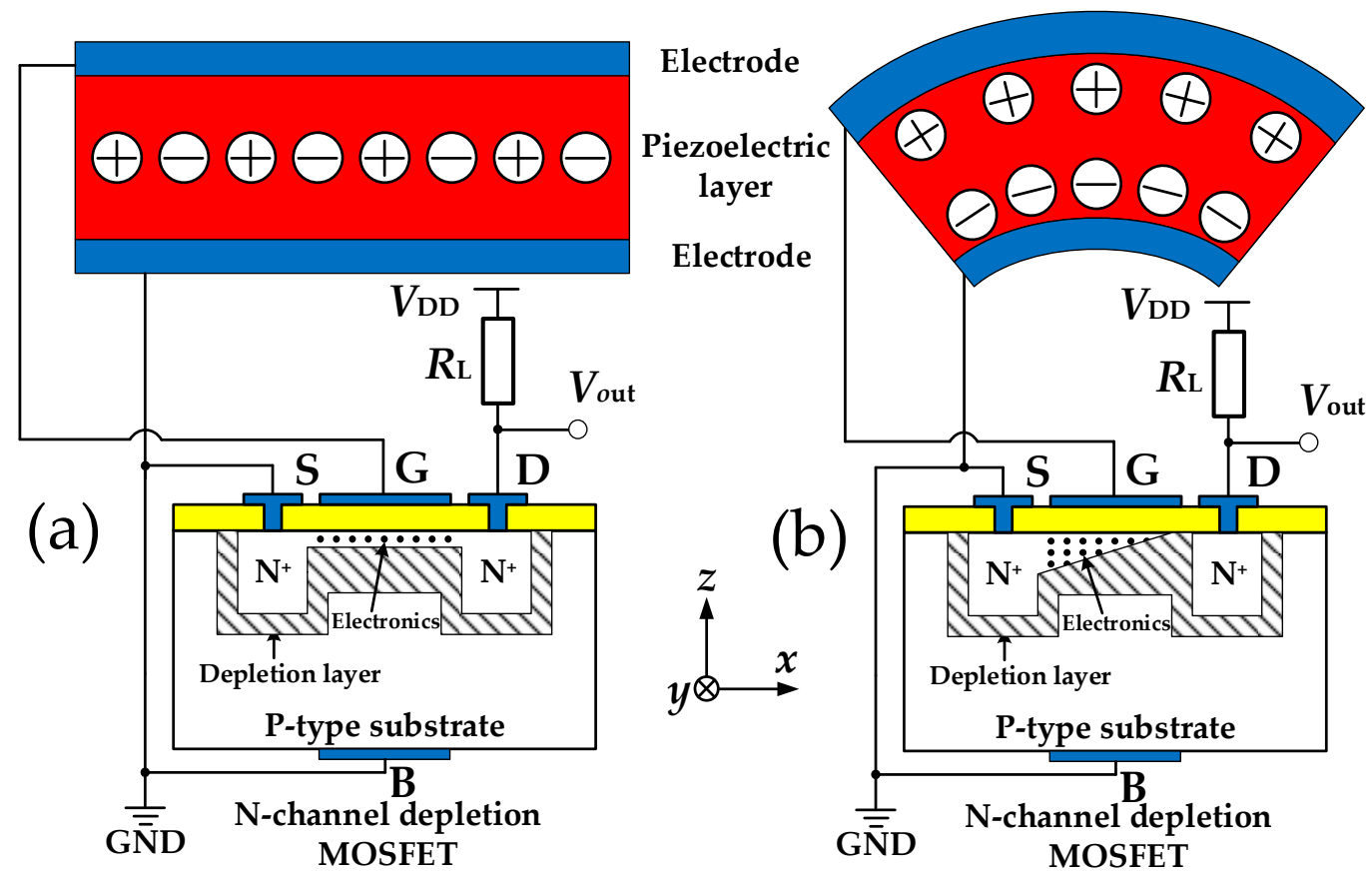

Figure 3. Working principle of piezoelectric PMAS: (a) without external acceleration; (b) with external acceleration.

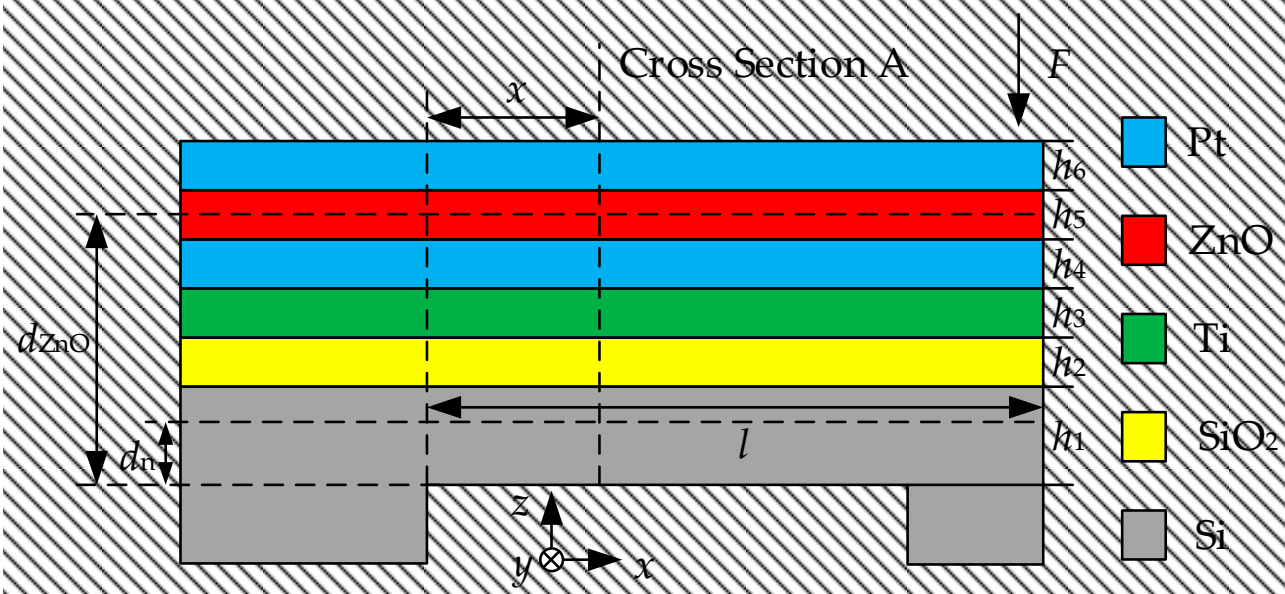

Figure 4. Stress analysis diagram of piezoelectric beam structure.

The main assumptions are as follows: (1) since the length and width are far greater than the thickness of the cantilever beam, it is considered that the cantilever beam has pure bending deformation and ignores the shear stress; (2) the beam bending caused by the residual stress is ignored; (3) the beam bending caused by the residual stress is ignored; (4) it is assumed that there is no relative sliding between each thin films; (5) the cantilever beam is in an open environment and there are no upper and lower fixed plates, so the influence of air damping is ignored [27-29].

According to the Euler-Bernoulli's equation, when the free end of the cantilever beam is subjected to a concentrated transverse force $F$, the stress on the cross section $\mathrm{A}$ of $\mathrm{ZnO}$ thin film is:

$$
\sigma_{\mathrm{A}}=\frac{M_{\mathrm{A}}}{I}\left|d_{\mathrm{ZnO}}-d_{\mathrm{n}}\right|=\frac{F \cdot x}{I}\left|d_{\mathrm{ZnO}}-d_{\mathrm{n}}\right|
$$

where $M_{\mathrm{A}}$ is the bending moment, $I$ is the moment of inertia of the multilayer structure. 
The equivalent width of layer $i$ relative to Si substrate is:

$$
w_{i}^{\prime}=\frac{E_{i}}{E_{\mathrm{Si}}} w_{\mathrm{Si}}, \mathrm{i}=1,2, \ldots, 6
$$

where $w_{i}^{\prime}$ is the width of each thin film, $E_{i}$ is the young's modulus, $i$ represents $\mathrm{Si}, \mathrm{SiO}, \mathrm{Ti}, \mathrm{Pt}, \mathrm{ZnO}$ and Pt layers, respectively.

Therefore, the equivalent sectional area $S_{\mathrm{i}}$ can be expressed as:

$$
S_{i}=w_{i} \cdot h_{i}, i=1,2, \ldots, 6
$$

The equivalent second moment of inertia of layer $i$ is:

$$
I_{i}^{\prime}=\frac{h_{i}^{3}}{12} w_{i}, i=1,2, \ldots, 6
$$

The distance from the $i$ layer to the bottom of Si substrate is:

$$
z_{i}=\sum_{i=1}^{6} h_{i}-\frac{h_{i}}{2}
$$

The distance from the neutral plane of the multilayer structure to the Si substrate is:

$$
z^{\prime}=\frac{\sum_{i=1}^{6} S_{i} d_{i}}{\sum_{i=1}^{6} S_{i}}
$$

The second moment of inertia is:

$$
I^{\prime}=\sum_{i=1}^{6}\left[I_{i}+S_{i}\left(z_{i}-z^{\prime}\right)^{2}\right]
$$

Substituting Equations (6) and (7) into (1), the cross-section stress of $\mathrm{ZnO}$ is:

$$
\sigma=\frac{F \cdot x \cdot\left|d_{\mathrm{ZnO}}-d_{\mathrm{n}}\right|}{\sum_{i=1}^{6}\left\{\frac{h_{i}^{3} w_{i}}{12}+S_{i}\left[\left(\sum_{i=1}^{6} h_{i}-\frac{h_{i}}{2}\right)-\frac{\sum_{i=1}^{6} S_{i} d_{i}}{\sum_{i=1}^{6} S_{i}}\right]\right)}, 0 \leq x \leq l
$$

According to the Hooke's law and the theories in mechanics of materials, a deflection $\delta$ will appear when a force $F$ is applied at the free end of the cantilever beam, and the deflection $\delta$ of the free end can be expressed as [30,31]:

$$
\delta=\frac{F}{k}=\frac{F l_{\mathrm{b}}{ }^{3}}{3 E I}=\frac{4 F l_{\mathrm{b}}{ }^{3}}{E w_{\mathrm{b}} h_{\mathrm{b}}^{3}}
$$

where $k$ is the stiffness of the cantilever beam.

The fundamental resonant frequency is [32]:

$$
f=\frac{\alpha_{n}^{2}}{2 \pi} \sqrt{\frac{E I}{m L^{4}}}
$$


where $E$ is the modulus of elasticity, $I$ is the area moment of inertia, $\alpha_{\mathrm{n}}$ is a constant which its value depends on the mode of cantilever beam's vibration, $m$ is the mass of the cantilever beam, $L$ is the length of the cantilever beam.

Considering the influence of the mass proof on the resonant frequency of cantilever beam, the first mode resonant frequency of the cantilever beam can be expressed as [33-35]:

$$
f=\frac{1.875^{2}}{2 \pi} \sqrt{\frac{0.236 E I}{\left(l_{b}-l_{m} / 2\right)^{3}\left(0.236 \rho h_{b} w_{b}\left(l_{b}-\frac{l_{m}}{2}\right)+\rho h_{b} w_{b} \frac{l_{m}}{2}+\rho h_{m} w_{m} l_{m}\right)}}
$$

where $\rho$ is the density of Si. The moment of inertia of multilayer structure is ignored due to the thickness of the multilayer structure being much less than that of the cantilever beam.

It can be seen that $l_{c}$ is inversely proportional to the $f$ frequency of the cantilever beam, and the change of $l_{c}$ has a greater impact on resonant frequency. Based on the piezoelectric effect, the surface charge density of $\mathrm{ZnO}$ is [26]:

$$
D_{3}=d_{31} \sigma
$$

Therefore, under the external acceleration, the charges generated by the piezoelectric beam are:

$$
\begin{aligned}
& q=\int_{0}^{w_{b}} \int_{0}^{l_{b}} D_{3} d x d y \\
& =\int_{0}^{w_{b}} \int_{0}^{l_{b}} d_{31} \sigma d x d y \\
& =\int_{0}^{w_{b}} \int_{0}^{l_{b}} \frac{d_{31} F x\left|d_{\mathrm{ZnO}}-d_{\mathrm{n}}\right|}{\sum_{i=1}^{6}\left\{\frac{h_{i}^{3} w_{i}}{12}+S_{i}\left[\left(\sum_{i=1}^{6} h_{i}-\frac{h_{i}}{2}\right)-\frac{\sum_{i=1}^{6} s_{i} d_{i^{\prime}}}{\sum_{i=1}^{6} s_{i}}\right]\right)} d x d y \\
& =\frac{w_{b} l_{b}^{2} d_{31} F\left|d_{\mathrm{ZnO}}-d_{\mathrm{n}}\right|}{2 \sum_{i=1}^{6}\left\{\frac{h_{i}^{3} w_{i}}{12}+S_{i}\left[\left(\sum_{i=1}^{6} h_{i}-\frac{h_{i}}{2}\right)-\frac{\sum_{i=1}^{6} s_{i} d_{i},}{\sum_{i=1}^{6} s_{i}}\right]\right.}
\end{aligned}
$$

The piezoelectric beam can be approximately considered as a parallel plate capacitor with a dielectric inside, so the output voltage $V_{\mathrm{B}}$ of the piezoelectric beam is:

$$
V_{\mathrm{B}}=\frac{q}{\mathrm{C}}
$$

In this case, due to the MOSFET works in the triode region, the relationship between source drain current $I_{\mathrm{DS}}$ and gate voltage $V_{\mathrm{GS}}$ can be expressed as follows [36]:

$$
I_{\mathrm{DS}}=\frac{\mu_{\mathrm{n}} W C_{\mathrm{ox}}}{L}\left[\left(V_{\mathrm{GS}}-V_{\mathrm{T}}\right) V_{\mathrm{DS}}-\frac{1}{2} V_{\mathrm{DS}}^{2}\right]
$$

where, $\mu_{\mathrm{n}}$ is dependent effective mobility, $W$ is the channel width, $L$ is the effective channel length, $C_{\mathrm{ox}}$ is the insulation capacitance, $V_{\mathrm{GS}}$ is the gate voltage which is equal to $V_{\mathrm{B}}, V_{\mathrm{T}}$ is the threshold voltage.

The output voltage of PMAS is:

$$
V_{\mathrm{out}}=V_{\mathrm{DD}}-V_{\mathrm{R}}=V_{\mathrm{DD}}-I_{\mathrm{DS}} R_{\mathrm{L}}
$$

Therefore, when the piezoelectric beam is connected to the gate of MOSFET, the output voltage of the piezoelectric beam is equal to $V_{\mathrm{GS}}$. With Equations (13)-(16), the relationship between $V_{\text {out }}$ and $F$ is:

$$
V_{\text {out }}=V_{\mathrm{DD}}-\frac{\mu_{\mathrm{n}} W C_{\mathrm{ox}}}{L}\left[\left(\frac{q}{C}-V_{\mathrm{T}}\right) V_{\mathrm{DS}}-\frac{1}{2} V_{\mathrm{DS}}^{2}\right] R_{\mathrm{L}}
$$

It can be seen from Equation (17) that the output voltage of the PMAS is proportional to the channel width-to-length ratio of the MOSFET. 


\section{Fabrication Technology}

Figure 5 shows the fabrication process of the piezoelectric beam. The n-type $<100>$ orientation silicon wafer was cleaned by the standard Radio Cooperation of America (RCA) process (Figure 5a), and the silicon dioxide layer was grown by the thermal oxidation method as the isolation layer (Figure $5 b$ ). In the manufacturing process of $\mathrm{Pt} / \mathrm{ZnO} / \mathrm{Pt} / \mathrm{Ti}$ piezoelectric multilayer structure, the lift-off process is selected to complete the fabrication of the piezoelectric multilayer structure. As shown in Figure $5 c-h$, firstly, the photoresist is evenly coated on the surface of the substrate layer, then patterned by photolithography. The Pt/Ti composite electrode is coated by RF magnetron sputtering, and the photoresist is removed by the stripping solution to complete the fabrication of the bottom electrode. $\mathrm{ZnO}$ layer and top electrode were also prepared by the lift-off process as the Pt/Ti bottom electrode. After that, the cantilever structure is released by twice photolithography and inductively coupled plasma (ICP) etching to complete the fabrication of the piezoelectric beam (Figure 5i-j). In order to improve the piezoelectric properties of the $\mathrm{ZnO}$ piezoelectric layer, we doped $\mathrm{ZnO}$ with lithium. $\mathrm{Li}$ atoms with a small atomic radius as acceptor impurities can increase the resistivity of the $\mathrm{ZnO}$ piezoelectric thin film and increase the output impedance, thereby achieving the purpose of improving the piezoelectric properties of $\mathrm{ZnO}$. During the preparation process, most of the doped lithium atoms will replace the positions of the zinc atoms and cause the decrease of the lattice constant. As a result, the residual stress in $\mathrm{ZnO}$ thin film is compressive stress [37].

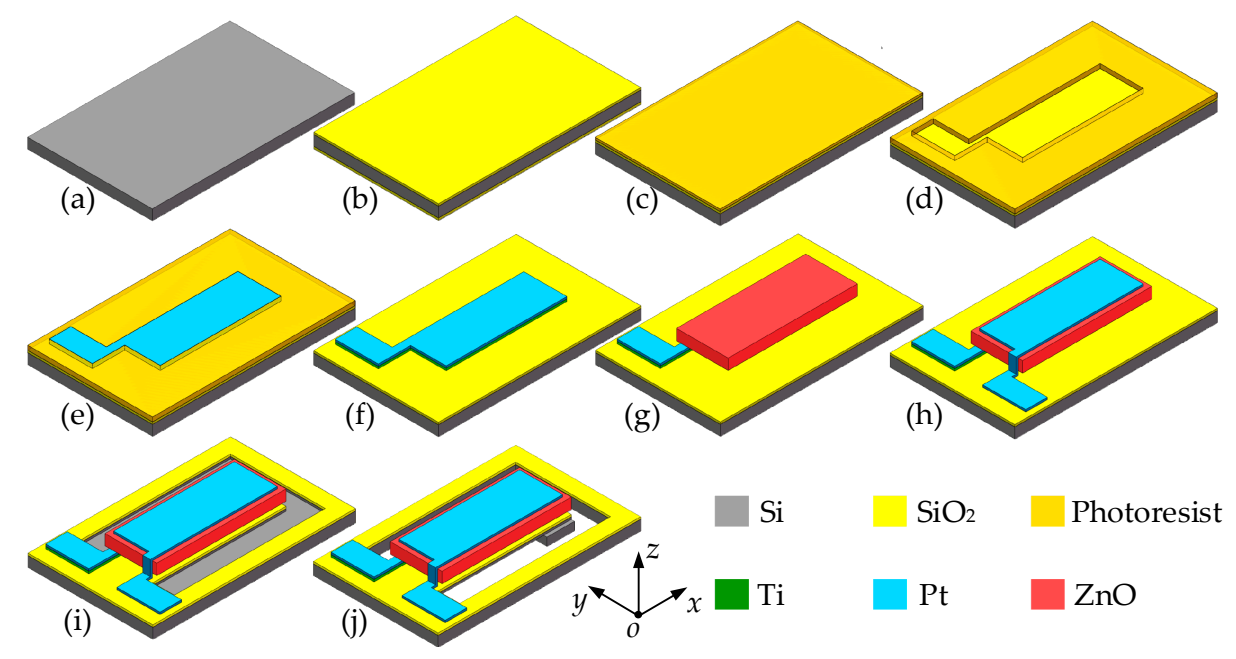

Figure 5. Fabrication process of the piezoelectric beam: (a) Si wafer; (b) growing $\mathrm{SiO}_{2}$; (c) coating photoresist; (d) patterning photoresist; (e) depositing Pt/Ti; (f) removing photoresist; (g) depositing $\mathrm{ZnO}$; (h) depositing Pt; (i) etching on the top side; (j) releasing cantilever beam.

\section{Results and Discussion}

\subsection{Test System}

Figure 6 shows the test system for the proposed acceleration sensor. It consisted of a standard vibrator (Dongling ESS-050, Dongling Vibration Test Instrument Co., Ltd., Suzhou, China), an oscilloscope (DSO-X 4154A, Agilent Technologies Inc., Santa Clara, CA, USA), a semiconductor characteristic analysis system (4200SCS, KEITHLEY 4200, Keithley, Cleveland, OH, USA) and a control computer. The system can apply acceleration from 0 to $30 \mathrm{G}$; the lower limit of the frequency is $50 \mathrm{~Hz}$, and the upper limit is $20,000 \mathrm{~Hz}$. 


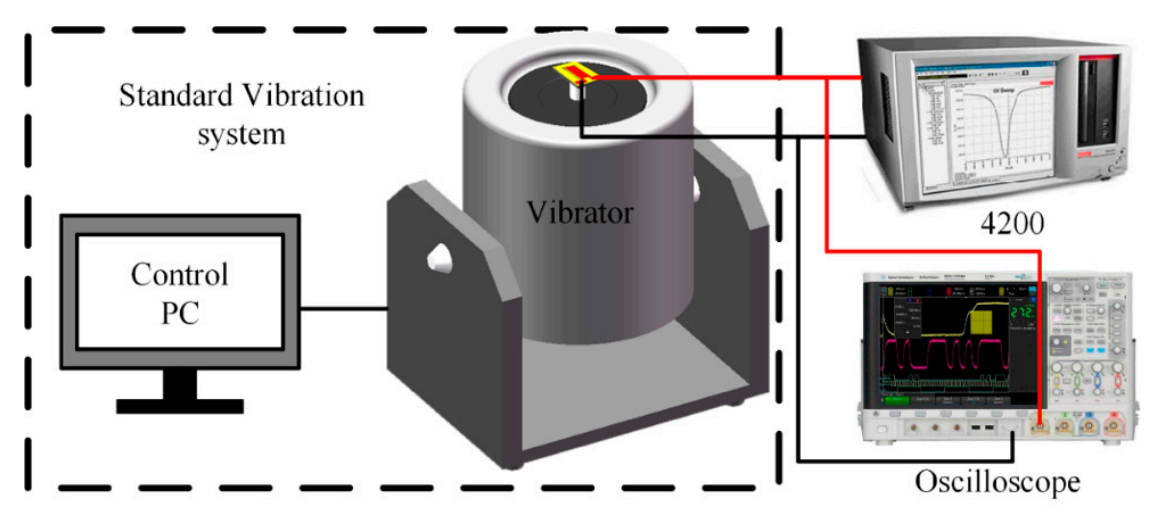

Figure 6. Testing system of acceleration sensor.

\subsection{Frequency Characteristic of the Piezoelectric Beam}

The frequency characteristic of the piezoelectric beam was analyzed by the sweep mode of the vibrator. The range of the excitation frequency was set from 20 to $2000 \mathrm{~Hz}$, and applied acceleration was $1 \mathrm{~g}$ constant along the $z$-axis direction of the piezoelectric beam. The piezoelectric beam was rigidly connected with the vibration table by a customized fixture. When the excitation frequency reached a certain value, the output of the piezoelectric beam reached its maximum value for the first time. At this time, the excitation frequency was the first resonance frequency of the piezoelectric beam. Figure $7 \mathrm{a}$ shows the relationship between the output voltage and the excitation frequency of the piezoelectric beam. When the excitation frequency reached $1072 \mathrm{~Hz}$, the output of the piezoelectric beam reached the maximum value of $0.649 \mathrm{~V}$. There is only one peak within $50-2000 \mathrm{~Hz}$, which proves that $1072 \mathrm{~Hz}$ is the first-order resonance frequency of the piezoelectric beam.
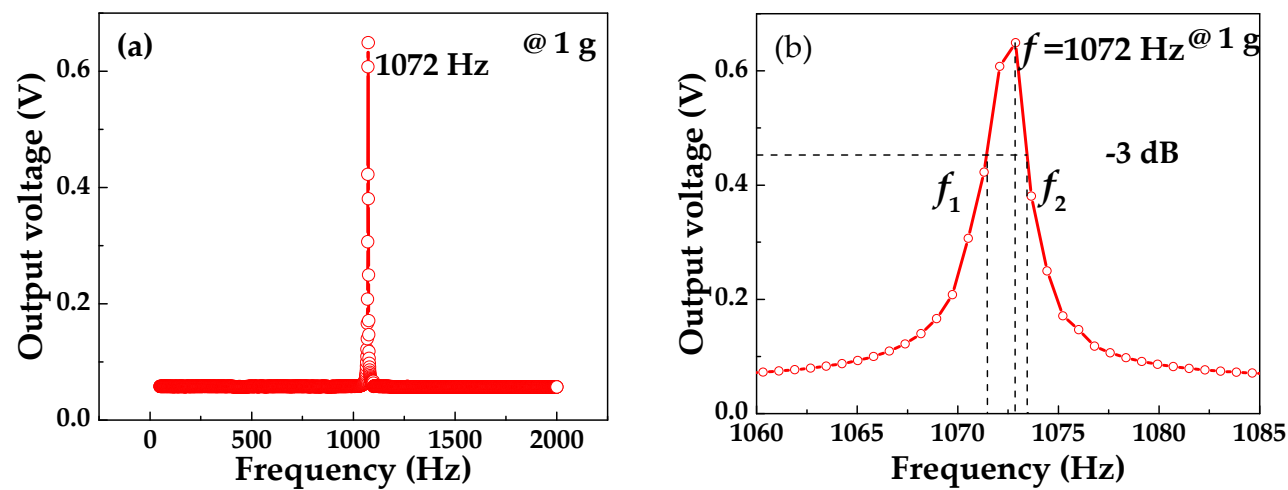

Figure 7. Relationship curve between output voltage and excitation frequency: (a) resonant frequency; (b) quality factor.

According to Figure 7a, the quality factor of the piezoelectric beam can be roughly analyzed as shown in Figure $7 \mathrm{~b}$. The quality factor $Q$ represents the energy dissipated by the body in overcoming the internal friction in resonance.

$$
Q=2 \pi \frac{E_{s}}{E_{c}}=\frac{f}{f_{1}-f_{2}}
$$

where $E_{\mathrm{s}}$ is the mechanical energy stored by the oscillator in the resonant state and $E_{\mathrm{c}}$ is the energy dissipated by the oscillator in the resonant state every cycle, $f$ is the resonance frequency and $f_{1}, f_{2}$ is the half power point frequency $(-3 \mathrm{~dB})$. From Figure $5 \mathrm{~b}$ we can estimate that $Q$ is 529.1.

Table 1 shows the design dimensions of piezoelectric beams. By substituting the data in Table 1 into Equation (10), the theoretical resonance frequency of the piezoelectric beam is $995 \mathrm{~Hz}$, which is lower than the test result $1072 \mathrm{~Hz}$. This is mainly due to the deviation of the thickness and length of the cantilever beam from the design value during the manufacturing process. 
Table 1. Theoretical calculation parameters of resonance frequency.

\begin{tabular}{ccccccccc}
\hline $\begin{array}{c}E \\
(\mathrm{GPa})\end{array}$ & $\begin{array}{c}\rho \\
\left(\mathrm{Kg} / \mathrm{m}^{3}\right)\end{array}$ & $\pi$ & $\begin{array}{c}l_{\mathrm{b}} \\
(\mu \mathrm{m})\end{array}$ & $\begin{array}{c}w_{\mathrm{b}} \\
(\mu \mathrm{m})\end{array}$ & $\begin{array}{c}h_{\mathrm{b}} \\
(\mu \mathrm{m})\end{array}$ & $\begin{array}{c}l_{\mathrm{m}} \\
(\mu \mathrm{m})\end{array}$ & $\begin{array}{c}w_{\mathrm{m}} \\
(\mu \mathrm{m})\end{array}$ & $\begin{array}{c}h_{\mathrm{m}} \\
(\mu \mathrm{m})\end{array}$ \\
\hline 190 & 2330 & 3.14 & 6000 & 2400 & 80 & 1000 & 2700 & 395 \\
\hline
\end{tabular}

\section{3. $I_{D S^{-}} V_{D S}$ Characteristic of MOSFET with Piezoelectric Beam}

The $I-V$ characteristic and transfer characteristic curves of the MOSFET were tested by 4200SCS, as shown in Figure 8a. Considering that the maximum limited current of 4200SCS is 0.1 A, the voltage range of $V_{\mathrm{GS}}$ was set from $-2.5 \mathrm{~V}$ to $-0.5 \mathrm{~V}$ with an increment of $-0.5 \mathrm{~V}$. Figure $8 \mathrm{~b}$ shows the transition characteristic curve of MOSFET, $V_{\mathrm{DS}}$ is $5 \mathrm{~V}$ in testing. It can be concluded that the pinch-off voltage of MOSFET $\left(V_{\mathrm{GS}(\text { off })}\right)$ is $-2.5 \mathrm{~V}$; with the increase of $V_{\mathrm{GS}}$, the $I_{\mathrm{DS}}$ also increases. When $V_{\mathrm{GS}}$ reaches $-0.45 \mathrm{~V}$, the limit current of the test instrument $0.1 \mathrm{~A}$ is reached.
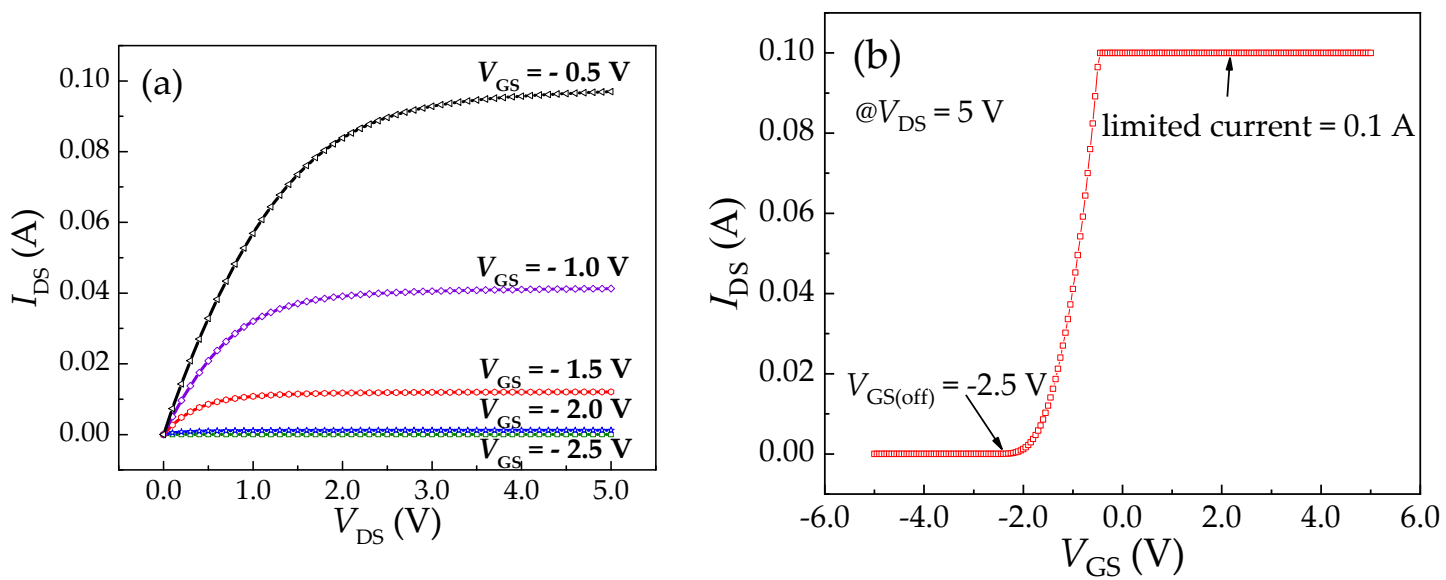

Figure 8. Characteristics curves of the MOSFET: (a) $I_{\mathrm{DS}}-V_{\mathrm{DS}}$ characteristics curves; (b) transition characteristic curve.

The test circuit shown in Figure 1b, 4200SCS, is connected with two output terminals of PMAS for data acquisition. The output voltage of the piezoelectric beam was used as gate voltage of MOSFET. In order to ensure that the output voltage of the piezoelectric beam can reach the maximum value, the test frequency was set at $1072 \mathrm{~Hz}$, which is the resonance frequency of the piezoelectric beam. The $I-V$ characteristic curves of the MOSFET are shown in Figure $9\left(V_{\mathrm{DD}}=5 \mathrm{~V}, R_{\mathrm{L}}=10 \mathrm{k} \Omega\right.$ and applied acceleration was $1.5 \mathrm{~g}$ ). Under the external acceleration generated by the stander vibration system, the proof mass drove the piezoelectric beam to vibrate up and down, which makes the $I_{\mathrm{DS}}$ of MOSFET fluctuate in a certain range. The maximum and minimum values of the wave range correspond to the maximum deformation of upward and downward bending of the piezoelectric beam, respectively. When $V_{\mathrm{DS}}$ is a certain value, the difference between the upper and the lower limit is $\Delta I_{\mathrm{DS}}$. With the increase of external excitation acceleration, the vibration amplitude of the piezoelectric beam increases and further increases the width of the curves. That means $\Delta I_{\mathrm{DS}}$ will increase with as acceleration increases. Because the signal produced by the piezoelectric beam is sinusoidal under the action of the stander vibration system, $\Delta I_{\mathrm{DS}}$ can be used as an important parameter to measure the output sensitivity of PMAS. In the test circuit of Figure $1 \mathrm{~b}$, by selecting appropriate load resistance $R_{\mathrm{L}}$, PMAS can amplify the signal of the piezoelectric beam so as to improve the sensitivity of output voltage. 


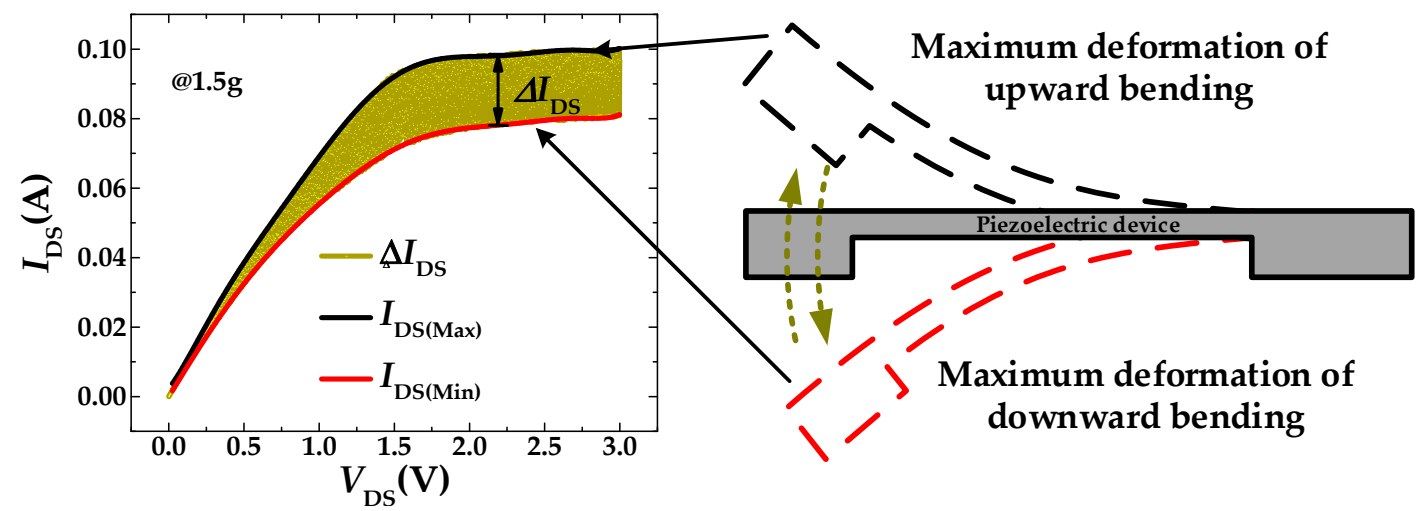

Figure 9. $I_{\mathrm{DS}}-V_{\mathrm{DS}}$ characteristics curves of the MOSFET with the piezoelectric beam.

\subsection{Sensitivity Characteristic of PMAS}

Figure 10a shows the output voltage curves of the piezoelectric beam and PMAS, where the peak-to-peak value of the output sinusoidal curves are defined as output voltage $V_{\text {piezo }}$ and $V_{\text {PMAS. }}$ $V_{\text {piezo }}$ increased from $0.287 \mathrm{~V}$ to $1.314 \mathrm{~V}$ at the excitation frequency of $1072 \mathrm{~Hz}$, and the acceleration range was from 0.2 to $1.4 \mathrm{~g}$. It can be concluded that $V_{\text {piezo }}$ increases with the increment of excitation acceleration, and the relationship between them is approximately linear. Figure $10 \mathrm{~b}$ shows the output voltage curve of the PMAS ( $\left.V_{\text {PMAS }}\right)$. In the conditions of excitation frequency of $1072 \mathrm{~Hz}$ and applied acceleration range from 0.2 to $1.4 \mathrm{~g}, V_{\text {PMAS }}$ increased from $0.327 \mathrm{~V}$ to $2.744 \mathrm{~V}$. Compared with $V_{\text {piezo, }}$ at the same condition $V_{\text {PMAS }}$ increased significantly and $V_{\text {PMAS }}$ was approximately linear with the excitation acceleration.
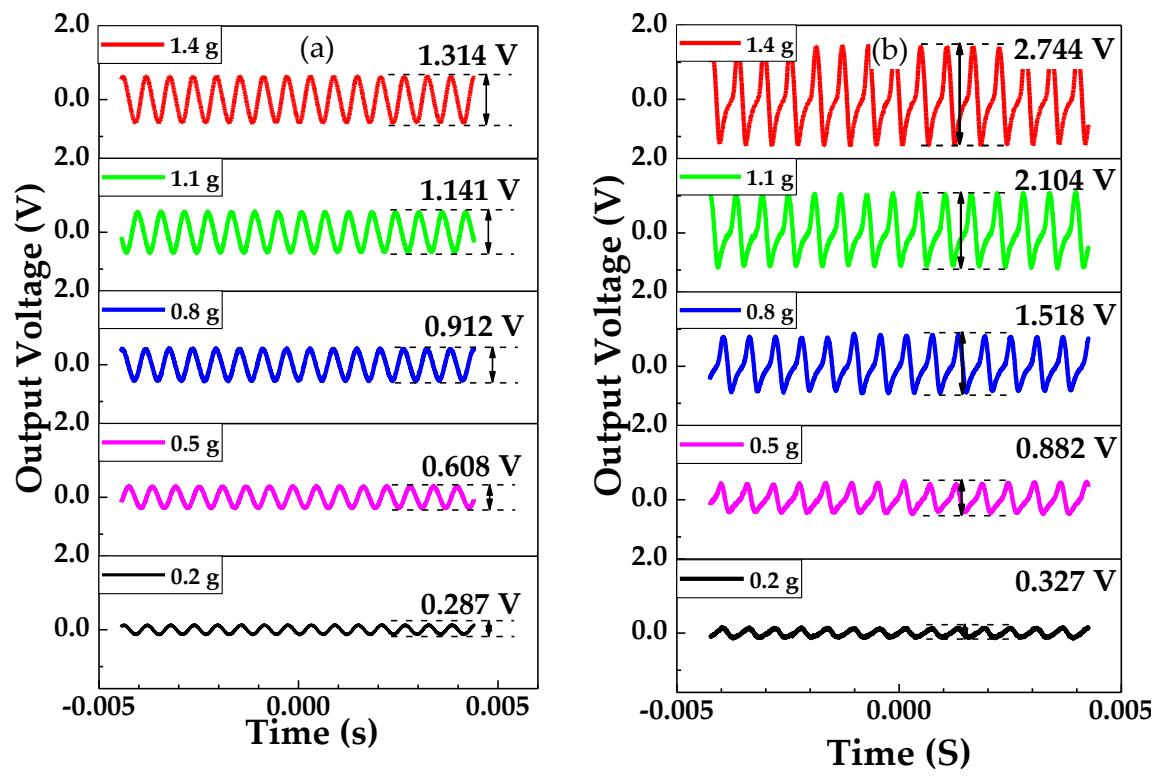

Figure 10. Output characteristics of the piezoelectric beam and PMA under the acceleration range from $0.2 \mathrm{~g}$ to $1.4 \mathrm{~g}$ : (a) output voltage curves of piezoelectric beam; (b) output voltage of PMAS.

According to Equation (13), the theoretical output voltage of the piezoelectric beam is $2.110 \mathrm{~V}$ under the acceleration condition of $1 \mathrm{~g}$, which is higher than the actual output voltage of $1.141 \mathrm{~V}$. The reason is that the thickness of the cantilever beam deviates from the theoretical value due to the uniformity error of ICP etching. The thickness of the cantilever beam is not uniform, which leads to the uneven distribution of stress when the cantilever beam is forced to bend. At the same time, there will be defects inside the $\mathrm{ZnO}$ piezoelectric thin film during the manufacturing process, which causes the charge generated by the stress to be less than the theoretical value. 
Figure 11 shows the comparison of $V_{\text {PMAS }}$ and $V_{\text {piezo }}$ with the increase of acceleration. It can be seen that under the same external acceleration, the output voltage of PMAS is significantly higher than that of piezoelectric beam. It means that MOSFET in PMAS plays a role of amplification. After that, two groups of output curves are fitted linearly, and it can be concluded that the two groups of curves have good linearity and the slopes of the fitting curves are the output voltage sensitivity of the two devices. The sensitivity of PMAS is $2.05 \mathrm{~V} / \mathrm{g}$, which is 2.41 times higher than that of the piezoelectric beam at $0.85 \mathrm{~V} / \mathrm{g}$. It proved that the PMAS structure can effectively improve the sensitivity of the piezoelectric beam. The charge output of the piezoelectric beam as the gate control voltage of the MOSFET can effectively convert the output charge into an output current, and it can also increase the load capacity of the piezoelectric acceleration sensor. However, the proposed sensor has a relatively narrow frequency range, which limits its application field. In addition, it can be seen from Equation (14) that the width-to-length ratio of the MOSFET is directly proportional to the output current. The $I_{\mathrm{DS}}$ can be improved by adjusting the aspect ratio of the MOSFET during the manufacturing process, thereby further improving the output sensitivity of the PMAS.

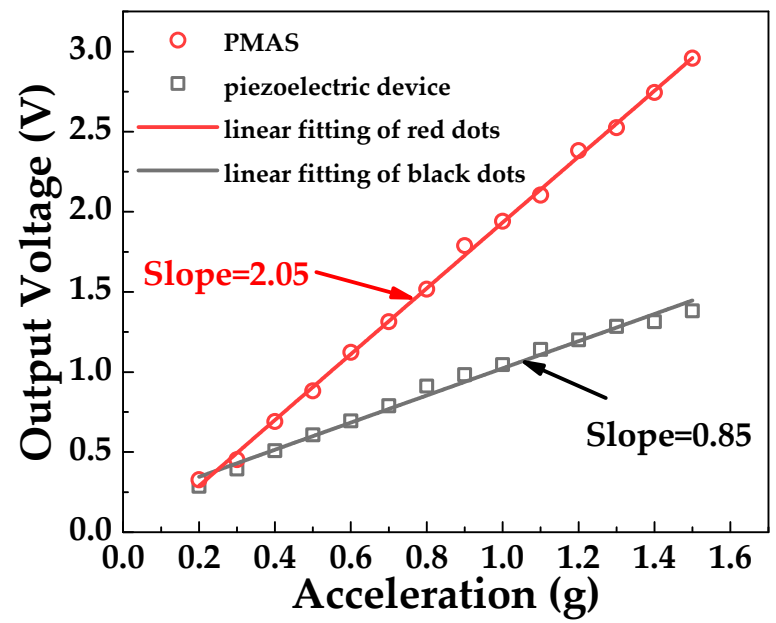

Figure 11. Relationship curves between output voltage and acceleration of PMAS and the piezoelectric beam.

Table 2 shows the performance comparison of piezoelectric acceleration sensors. The proposed sensor has certain advantages in sensitivity, but does not dominate in terms of chip size. It can also be seen from the comparison that piezoelectric acceleration sensors have higher sensitivity, but at a disadvantage in terms of measurement range and load capacity.

Table 2. Performance comparison of the proposed sensor with others.

\begin{tabular}{lcccc}
\hline Transduction & Material & Die Area $\left(\mathbf{m m}^{\mathbf{2}}\right)$ & Sensitivity $\mathbf{( V / g )}$ & Reference \\
\hline Piezoelectric & Li doped $\mathrm{ZnO}$ & $9.8 \times 5.8$ & 2.05 at resonance frequency & this work \\
Piezoelectric & AlN & $2.3 \times 2.3$ & 0.355 & {$[38]$} \\
Piezoelectric & V doped ZnO & - & 3.528 at resonance frequency & {$[25]$} \\
Piezoelectric & V doped ZnO & - & 1.9 at resonance frequency & {$[39]$} \\
piezoresistive & $\mathrm{Si}$ & $3.5 \times 3.5$ & 0.004 & {$[40]$} \\
piezoresistive & $\mathrm{Si}$ & $2 \times 2$ & 0.106 & {$[41]$} \\
\hline
\end{tabular}

\section{Conclusions}

In summary, this paper proposed a high sensitivity piezoelectric acceleration sensor. It consisted of a piezoelectric beam and an N-channel depletion MOSFET. Utilizing the advantage of MOSFET's high input impedance, the output signal of the piezoelectric beam was used to drive the MOSFET, thereby converting the output charge of the piezoelectric beam into output current, and improving the sensitivity of the piezoelectric acceleration sensor. The results show that the resonance frequency 
of the piezoelectric beam was $1072 \mathrm{~Hz}$ and the sensitivity of the proposed sensor was $2.05 \mathrm{~V} / \mathrm{g}$ at the resonance frequency, which is 2.41-times higher than that of the piezoelectric beam. This research provides a good foundation for the integration of piezoelectric MOSFETs in the future. In future work, continuing to improve the sensitivity of piezoelectric acceleration sensors is an important research direction for us. We will improve the output sensitivity of the PMAS by optimizing the width-to-length ratio of MOSFETs and improving the manufacturing process of piezoelectric materials, while at the same time optimizing the cantilever beam structure to increase its frequency range.

Author Contributions: C.A. and X.Z. wrote the manuscript; X.Z. and D.W. designed the project; C.A. performed the experiments; C.A. and X.Z. contributed to the data analysis. All authors have read and agreed to the published version of the manuscript.

Funding: This research was supported by the National Natural Science Foundation of China (No. 61971180), project of the central government supporting the reform and development of local colleges and universities. Basic Scientific Research Project of the Provincial Higher University in Heilongiang Province (KJCXZD201705).

Conflicts of Interest: The authors declare no conflict of interest.

\section{References}

1. Krishnamoorthy, U.; Olsson, R.H.; Bogart, G.R.; Baker, M.S.; Carr, D.W.; Swiler, T.P.; Clews, P.J. In-plane MEMS-based nano-g accelerometer with sub-wavelength optical resonant sensor. Sens. Actuator A Phys. 2008, 145, 283-290. [CrossRef]

2. $\mathrm{Xu}, \mathrm{R} . ; \mathrm{Zhou}, \mathrm{S} . ; \mathrm{Li}, \mathrm{W} . J$. MEMS Accelerometer Based Nonspecific-User Hand Gesture Recognition. IEEE Sens. J. 2012, 12, 1166-1173. [CrossRef]

3. Hongwei, Q.; Deyou, F.; Huikai, X. A Monolithic CMOS-MEMS 3-Axis Accelerometer With a Low-Noise, Low-Power Dual-Chopper Amplifier. IEEE Sens. J. 2008, 8, 1511-1518. [CrossRef]

4. Pak, M.; Fernandez, F.V.; Dundar, G. A novel design methodology for the mixed-domain optimization of a MEMS accelerometer. Integration 2018, 62, 314-321. [CrossRef]

5. Gesing, A.L.; Masson, Z.N.; Arellano, D.C.; Alves, F.; Paul, S.; Cordioli, J.A. Middle Ear Ossicular Chain Vibration Detection by Means of an Optimized MEMS Piezoelectric Accelerometer. IEEE Sens. J. 2019, 19, 2079-2086. [CrossRef]

6. Yang, J.; Zhang, M.; He, Y.; Su, Y.; Han, G.; Si, C.; Ning, J.; Yang, F.; Wang, X. A Resonant Z-Axis Aluminum Nitride Thin-Film Piezoelectric MEMS Accelerometer. Micromachines 2019, 10, 589. [CrossRef]

7. Wang, S.; Wei, X.; Zhao, Y.; Jiang, Z.; Shen, Y. A MEMS resonant accelerometer for low-frequency vibration detection. Sens. Actuator A Phys. 2018, 283, 151-158. [CrossRef]

8. Shi, Y.; Zhao, Y.; Feng, H.; Cao, H.; Tang, J.; Li, J.; Zhao, R.; Liu, J. Design, fabrication and calibration of a high-G MEMS accelerometer. Sens. Actuator A Phys. 2018, 279, 733-742. [CrossRef]

9. Xu, J.; Bertke, M.; Li, X.; Mu, H.; Zhou, H.; Yu, F.; Hamdana, G.; Schmidt, A.; Bremers, H.; Peiner, E. Fabrication of ZnO nanorods and Chitosan@ZnO nanorods on MEMS piezoresistive self-actuating silicon microcantilever for humidity sensing. Sens. Actuators B Chem. 2018, 273, 276-287. [CrossRef]

10. Zhao, Y.; Li, X.; Liang, J.; Jiang, Z. Design, fabrication and experiment of a MEMS piezoresistive high-g accelerometer. J. Mech. Sci. Technol. 2013, 27, 831-836. [CrossRef]

11. Liu, H.; Fang, R.; Miao, M.; Zhang, Y.; Yan, Y.; Tang, X.; Lu, H.; Jin, Y. Design, Fabrication, and Performance Characterization of LTCC-Based Capacitive Accelerometers. Micromachines 2018, 9, 120. [CrossRef] [PubMed]

12. Wang, Y.-H.; Song, P.; Li, X.; Ru, C.; Ferrari, G.; Balasubramanian, P.; Amabili, M.; Sun, Y.; Liu, X. A Paper-Based Piezoelectric Accelerometer. Micromachines 2018, 9, 19. [CrossRef] [PubMed]

13. Zou, Q.; Tan, W.; Kim, E.S.; Loeb, G.E. Single-and Triaxis Piezoelectric-Bimorph Accelerometers. J. Microelectromech. Syst. 2008, 17, 45-57. [CrossRef]

14. Zhao, X.; Wang, Y.; Wen, D. Fabrication and Characteristics of a SOI Three-Axis Acceleration Sensor Based on MEMS Technology. Micromachines 2019, 10, 238. [CrossRef]

15. Hu, X.; Mackowiak, P.; Bauscher, M.; Ehrmann, O.; Lang, K.D.; Schneider-Ramelow, M.; Linke, S.; Ngo, H.D. Design and Application of a High-G Piezoresistive Acceleration Sensor for High-Impact Application. Micromachines 2018, 9, 266. [CrossRef] [PubMed] 
16. Wang, Y.; Zhao, X.; Wen, D. Fabrication and Characteristics of a Three-Axis Accelerometer with Double L-Shaped Beams. Sensors 2020, 20, 1780. [CrossRef]

17. Won, D.J.; Huh, M.; Lee, S.; Park, U.; Yoo, D.; Kim, J. Capacitive-Type Two-Axis Accelerometer with Liquid-Type Proof Mass. Adv. Electron. Mater. 2020, 6. [CrossRef]

18. Mukhiya, R.; Agarwal, P.; Badjatya, S.; Garg, M.; Gaikwad, P.; Sinha, S.; Singh, A.K.; Gopal, R. Design, modelling and system level simulations of DRIE-based MEMS differential capacitive accelerometer. Microsyst. Technol. 2019, 25, 3521-3532. [CrossRef]

19. Zhang, H.; Wei, X.; Ding, Y.; Jiang, Z.; Ren, J. A low noise capacitive MEMS accelerometer with anti-spring structure. Sens. Actuator A Phys. 2019, 296, 79-86. [CrossRef]

20. Scheeper, P.; Gulløv, J.O.; Kofoed, L.M. A piezoelectric triaxial accelerometer. J. Micromech. Microeng. 1996, 6, 131-133. [CrossRef]

21. Ghoddus, H.; Kordrostami, Z.; Amiri, P. Performance enhancement of MEMS-guided four beam piezoelectric transducers for energy harvesting and acceleration sensing. Int. J. Mod. Phys. B 2019, 33. [CrossRef]

22. Tsai, C.C.; Chien, Y.C.; Hong, C.S.; Chu, S.Y.; Wei, C.L.; Liu, Y.H.; Kao, H.Y. Study of Pb(Zr $0.52 \mathrm{Ti} 0.48$ )O3 microelectromechanical system piezoelectric accelerometers for health monitoring of mechanical motors. J. Am. Ceram. Soc. 2019, 102, 4056-4066. [CrossRef]

23. Zhang, D.; Liu, J.; Qin, L.; Liu, J.; Li, M. Multiparameter Modeling of Piezoelectric Six-Degree-of-Freedom Accelerometer About Sensitivity Characteristics. IEEE Sens. J. 2020, 20, 7129-7137. [CrossRef]

24. Wang, Y.; Ding, H.; Le, X.; Wang, W.; Xie, J. A MEMS piezoelectric in-plane resonant accelerometer based on aluminum nitride with two-stage microleverage mechanism. Sens. Actuators A Phys. 2017, 254, 126-133. [CrossRef]

25. Ramany, K.; Shankararajan, R.; Savarimuthu, K.; Elumalai, P.; Rajamanickam, G.; Narendhiran, S.; Perumalsamy, R. Experimental Study of Different Vanadium Dopant Concentrations in ZnO Nanorods for a Low Frequency Piezoelectric Accelerometer. J. Electron. Mater. 2019, 48, 5310-5322. [CrossRef]

26. Ai, C.; Zhao, X.; Li, S.; Li, Y.; Bai, Y.; Wen, D. Fabrication and Characteristic of a Double Piezoelectric Layer Acceleration Sensor Based on Li-Doped ZnO Thin Film. Micromachines 2019, 10, 331. [CrossRef]

27. Zhang, W.; Meng, G. Nonlinear dynamical system of micro-cantilever under combined parametric and forcing excitations in MEMS. Sens. Actuator A Phys. 2005, 119, 291-299. [CrossRef]

28. Ahn, Y.; Guckel, H.; Zook, J.D. Capacitive microbeam resonator design. J. Micromech. Microeng. 2001, 11, 70-80. [CrossRef]

29. Arias, F.J.; De Las Heras, S. The use of compliant surfaces for harvesting energy from water streams. Energy 2019, 189. [CrossRef]

30. Tan,Z.-Q.; Chen, Y.-C. Size-dependent electro-thermo-mechanical analysis of multilayer cantilever microactuators by Joule heating using the modified couple stress theory. Compos. Part B Eng. 2019, 161, 183-189. [CrossRef]

31. Xu, Z.; Huang, H.; Dong, J. A stick-slip piezoelectric actuator with measurable contact force. Mech. Syst. Signal Process. 2020, 144. [CrossRef]

32. Joshi, S.; Nayak, M.M.; Rajanna, K. Evaluation of Transverse Piezoelectric Coefficient of ZnO Thin Films Deposited on Different Flexible Substrates: A Comparative Study on the Vibration Sensing Performance. ACS Appl. Mater. Interfaces 2014, 6, 7108-7116. [CrossRef] [PubMed]

33. Shih, W.Y.; Li, X.; Gu, H.; Shih, W.-H.; Aksay, I.A. Simultaneous liquid viscosity and density determination with piezoelectric unimorph cantilevers. J. Appl. Phys. 2001, 89, 1497-1505. [CrossRef]

34. Shen, D.; Park, J.-H.; Noh, J.H.; Choe, S.-Y.; Kim, S.-H.; Wikle, H.C.; Kim, D.-J. Micromachined PZT cantilever based on SOI structure for low frequency vibration energy harvesting. Sens. Actuator A Phys. 2009, 154, 103-108. [CrossRef]

35. Shen, D.; Park, J.-H.; Ajitsaria, J.; Choe, S.-Y.; Wikle, H.C.; Kim, D.-J. The design, fabrication and evaluation of a MEMS PZT cantilever with an integrated Si proof mass for vibration energy harvesting. J. Micromech. Microeng. 2008, 18. [CrossRef]

36. Ortiz-Conde, A.; Sucre-González, A.; Zárate-Rincón, F.; Torres-Torres, R.; Murphy-Arteaga, R.S.; Liou, J.J.; García-Sánchez, F.J. A review of DC extraction methods for MOSFET series resistance and mobility degradation model parameters. Microelectron. Reliab. 2017, 69, 1-16. [CrossRef]

37. Song, M.; Liu, Y.; Yu, A.; Zhang, Y.; Zhai, J.; Wang, Z.L. Flexible Li-doped ZnO piezotronic transistor array for in-plane strain mapping. Nano Energy 2019, 55, 341-347. [CrossRef] 
38. Yaghootkar, B.; Azimi, S.; Bahreyni, B. A High-Performance Piezoelectric Vibration Sensor. IEEE Sens. J. 2017, 17, 4005-4012. [CrossRef]

39. Ramany, K.; Shankararajan, R.; Savarimuthu, K.; Elumalai, P.; Rajamanickam, G.; Narendhiran, S.; Perumalsamy, R. Comparative study on hydrothermally synthesized undoped and Vanadium doped Zinc Oxide nanorods for nanoelectromechanical systems low-frequency accelerometer application. Thin Solid Films 2019, 680, 60-66. [CrossRef]

40. Roy, A.L.; Sarkar, H.; Dutta, A.; Bhattacharyya, T.K. A high precision SOI MEMS-CMOS \pm 4 g piezoresistive accelerometer. Sens. Actuator A Phys. 2014, 210, 77-85. [CrossRef]

41. Huang, S.; Li, X.; Song, Z.; Wang, Y.; Yang, H.; Che, L.; Jiao, J. A high-performance micromachined piezoresistive accelerometer with axially stressed tiny beams. J. Micromech. Microeng. 2005, 15, 993-1000. [CrossRef]

(C) 2020 by the authors. Licensee MDPI, Basel, Switzerland. This article is an open access article distributed under the terms and conditions of the Creative Commons Attribution (CC BY) license (http://creativecommons.org/licenses/by/4.0/). 